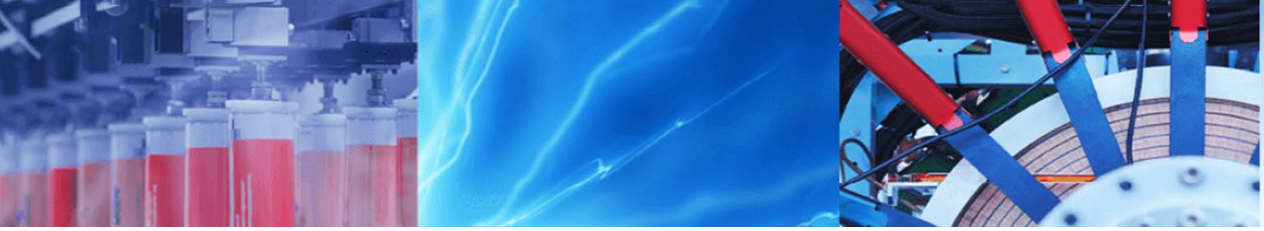

Research Article

\title{
Artificial bee colony algorithm to forecast natural gas consumption of Turkey
}

\author{
Oğuzhan Ahmet Arık ${ }^{1}$ (I)
}

(c) Springer Nature Switzerland AG 2019

\begin{abstract}
Natural gas is one of the most important energy sources in the world because it is cheaper and cleaner than most of its alternatives. Therefore, natural gas is used for residential and industrial purposes such as heating, electricity generation and manufacturing. Although Turkey has its own resources to meet the demand for natural gas, most of the needed natural gas amount is imported from other countries. The produced or imported natural gas has been used for heating, electricity generation and manufacturing in Turkey. Therefore approximate forecasting with a less statistical error of vital energy sources such as natural gas is extremely significant for countries having an imbalance between export and import values. The main purpose of this study is to determine the best coefficients with less statistical error for the forecasting equation for natural gas demand of Turkey. This paper suggests an Artificial Bee Colony $(A B C)$ algorithm for forecasting natural gas consumption in billion cubic meters $(\mathrm{bcm})$ for the years between 2018 and 2030 by using some historical indicators between 1998 and 2017. ABC algorithm is firstly used for determining coefficients of a forecasting equation for natural gas demand of Turkey. $A B C$ algorithm was originally designed for continuous optimization problems and with its simple structure and applicability can be useful for decision or policymakers. Therefore such a strong metaheuristic algorithm in the literature should be used for a vital problem of the countries having current account deficit like Turkey. Annual gross domestic product at chained volume index, population, export and import of Turkey are selected as historical indicators and independent variables for forecasting in this study. Furthermore, a linear regression model is also created to compare the proposed forecasting model. Both models are used to forecast Turkey future natural gas consumption for two different scenarios. The proposed algorithm outperforms the linear regression model in view of total absolute relative errors from previous natural gas consumptions of Turkey.
\end{abstract}

Keywords Artificial bee colony · Natural gas consumption · Forecasting · Linear regression · Turkey

\section{List of symbols}

Abbreviations

$A B C$

ABC_NGD

$B C M$

GA

GDP

GDP_Index

LR_NGD
Artificial bee colony

Artificial bee colony algorithm to forecast

natural gas demand

Billion cubic meters

Genetic algorithm

Gross domestic product

GDP at chained volume index

Linear regression to forecast natural gas

demand

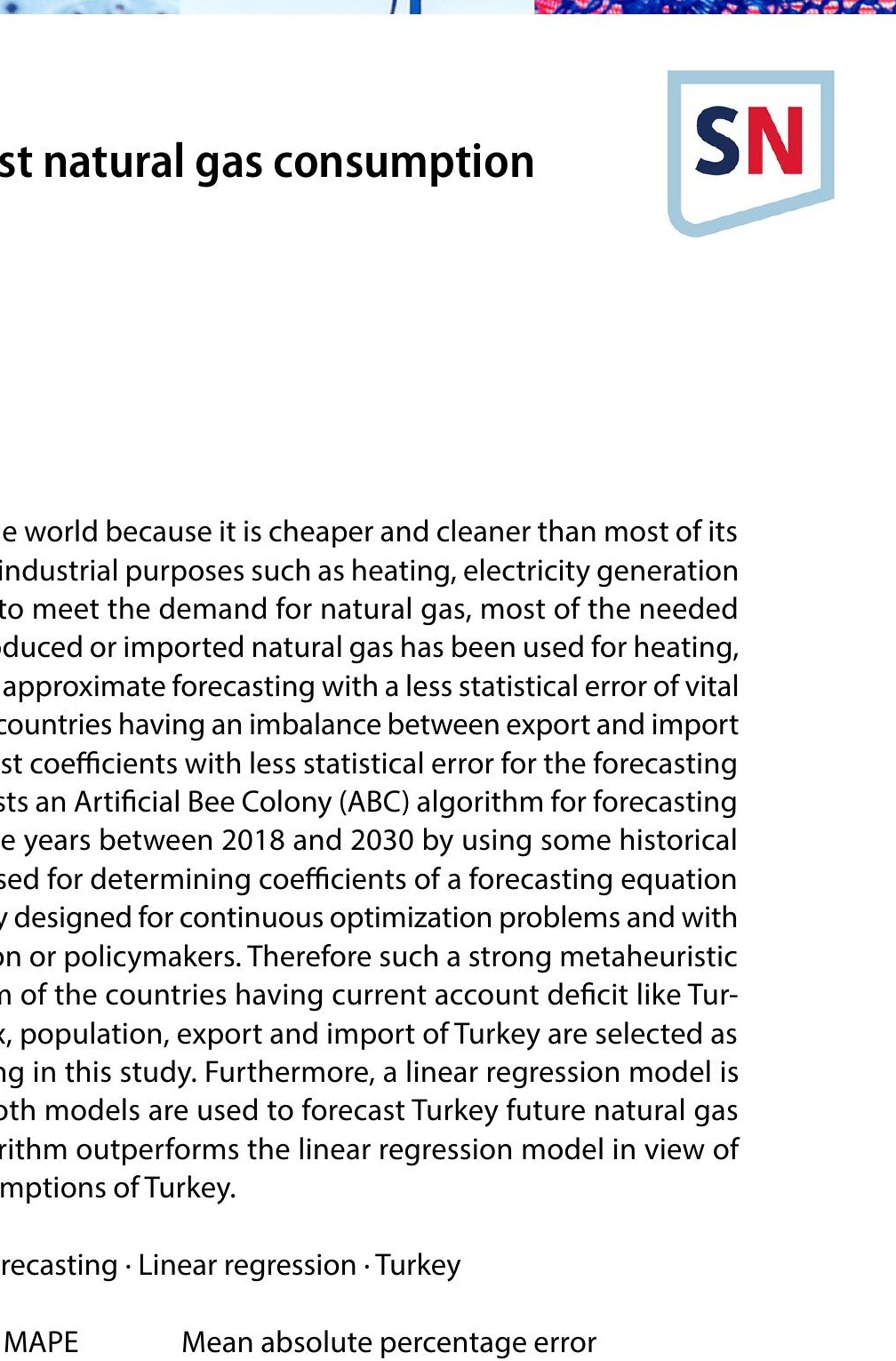

MAPE Mean absolute percentage error

NGD Natural gas demand

RE Relative error

SA Simulated annealing

SAGA Simulated annealing with

TurkStat Turkish Statistical Institute

Notation

$A_{t} \quad$ The observed NGD for year $t$

$f(\vec{\beta}) \quad$ The objective function value obtained by

using $\vec{\beta}$ coefficient vector where

$\vec{\beta}=\left(\beta_{0}, \beta_{1}, \beta_{2}, \beta_{3}, \beta_{4}\right)$

Oğuzhan Ahmet Arık, oaarik@nny.edu.tr| '1 Industrial Engineering Department, Nuh Naci Yazgan University, 38170 Kayseri, Turkey.

SN Applied Sciences (2019) 1:1138 | https://doi.org/10.1007/s42452-019-1195-8

Received: 21 June 2019 / Accepted: 28 August 2019 / Published online: 3 September 2019 


\begin{tabular}{|c|c|}
\hline$F_{t}(\vec{\beta})$ & \\
\hline fitness $_{i}\left(\vec{\beta}_{i}\right)$ & $\begin{array}{l}\text { coefficient vector } \\
\text { The fitness value of } \vec{\beta} \text {. coefficient vector }\end{array}$ \\
\hline failure $_{j}\left(\vec{\beta}_{j}\right)$ & The counter how many times $\vec{\beta}_{i}$ coefficient \\
\hline & $\begin{array}{l}\text { vector is failed to produce new better } \\
\text { coefficient vector }\end{array}$ \\
\hline ui & $\begin{array}{l}\text { The upper bound of ith independent vari- } \\
\text { able in } \vec{\beta} \text { coefficient vector }\end{array}$ \\
\hline$l_{i}$ & $\begin{array}{l}\text { The lower bound of ith independent vari- } \\
\text { able in } \vec{\beta} \text { coefficient vector }\end{array}$ \\
\hline & Random real number between $[-1,1]$ \\
\hline$p_{j}$ & $\begin{array}{l}\text { Selection probability of } \vec{\beta}_{j} \text { coefficient } \\
\text { vector }\end{array}$ \\
\hline$v_{j i}$ & $\begin{array}{l}\text { New coefficient for ith independent } \\
\text { variable }\end{array}$ \\
\hline$Y_{A B C \_N G D}$ & $\begin{array}{l}\text { The natural gas demand forecasting equa- } \\
\text { tion of } A B C \text { model }\end{array}$ \\
\hline & $\begin{array}{l}\text { The natural gas demand forecasting equa- } \\
\text { tion of LR model }\end{array}$ \\
\hline
\end{tabular}

\section{Introduction}

Natural gas, used for heating and electricity generation, has become one of the important energy sources in the world since it provides low-level emission of greenhouse gases and has significant economic and other environmental benefits [1]. After the 1980s, Turkey has started to grow in production so its energy needs for production has dramatically grown. As a result of this, Turkey's own energy resources have been inadequate to meet the demand for energy and Turkey's balance of payment has started to be uncontrolled so current account deficit has been the main macroeconomic problem of Turkey. Energy import is the leader of the main reasons causing current account deficit in Turkey. Natural gas importing has a significant effect on total energy import of Turkey. In recent years, natural gas consumption has become the fastest growing primary energy source in Turkey. Natural gas becomes an increasingly central component of energy consumption in Turkey [2]. For instance, in between 1990 and 2018; the total produced natural gas in Turkey is 14.11 billion cubic meters $(\mathrm{bcm})$ and total consumed natural gas in Turkey is $700.34 \mathrm{bcm}$ [3]. On average, the energy demand of Turkey is mounting by $8 \%$ annually, one of the highest rates in the world [4]. It can be easily understood that forecasting of critical energy resources' consumption such as natural gas has immense importance for countries having current account deficit like Turkey.

Because of current account deficit in Turkey, many researchers investigated further energy demand of Turkey in the literature. As far as we know, the first paper that tries to estimate natural gas consumption/demand (NGD) for Turkey was conducted by Sarak and Satman [5]. They used the heating degree-day method to determine natural gas consumption by residential heating in Turkey. The first paper used a metaheuristic algorithm to estimate NGD of Turkey was considered by Öztürk et al. [6]. They developed an energy input estimation equations for the residentialcommercial sector in order to estimate the future projections based on genetic algorithm (GA). In their study, they proposed a quadratic forecasting equation that depends on population, gross domestic product (GDP), export, import, residential housing production and cement production, house appliances sales of refrigerator, washing machine, television and vacuum cleaner figures of Turkey. Aras [7] presented an application of GAs to forecast shortterm demand for natural gas in residences in Turkey. Aras [7] assumed that residential demand is a function of time, heating degree-day value, and consumer price index. Therefore, Aras proposed a GA to estimate parameters of a multiple nonlinear regression model which mathematically represents the relationship between natural gas consumption and influential variables. Toksarı [8] developed a simulated annealing (SA) algorithm to forecast further NGD of Turkey by using some historical indicators, such as GDP, population, import, and export. Toksarı [8] used linear and quadratic forecasting equations in his proposed SA and he forecasted NGD of Turkey until 2025. Furthermore, Toksarı [8] stated that the quadratic forecasting equation presents a better fit solution compared to a linear forecasting equation. Olgun et al. [9] investigated the support vector machines and artificial neural networks models in order to estimate the natural gas demand of Turkey. They preferred historical GDP and population values of Turkey as independent variables. They also stated that support vector machines have less statistical error comparing to artificial neural networks for demand estimation of natural gas consumption in Turkey. Taşpınar et al. [10] proposed a multilayer perceptron the artificial neural networks with time series approach for forecasting short-term NGD values of Turkey's certain regions by using a data set including daily residential natural gas consumption, air temperature, average cloud cover, relative humidity, atmospheric pressure and wind speed as input variables for 4 years between 2007 and 2011. Melikoğlu [11] proposed two semi-empirical models based on econometrics, GDP at purchasing power parity per capita, and demographics, population change. Melikoğlu [11] used a logistic equation for long term natural gas demand forecasting and used a linear equation for medium-term demand forecasting. Boran [1] studied a grey prediction with a rolling mechanism to predict Turkey's NGD. Akpınar and Yumusak [12] studied time series decomposition, Holt-Winters 
exponential smoothing and autoregressive integrated moving average methods to forecast NGD of Sakarya province in Turkey. Ozdemir et al. [13] proposed GA, SAGA (simulated annealing with a genetic algorithm) and a linear regression model for forecasting NGD of Turkey in years between 2010 and 2030 by using GDP, population and growth rate of Turkey in years between 1985 and 2009. They stated that SAGA makes forecasts with less statistical error against linear regression. Akpinar et al. [14] proposed an artificial bee colony-based artificial neural networks (ANN-ABC) to forecast day-ahead NGD with a lower statistical error. They stated that $A N N-A B C$ is a strong, stable, and effective method with a low error rate of 14.9 mean absolute percentage error for training utilizing mean absolute percentage error (MAPE) with a univariate sliding window technique. Karadede et al. [15] proposed a Breeder hybrid algorithm consisting of the constitution of nonlinear regression-based Breeder genetic algorithm and simulated annealing is proposed for the objective of forecasting the NGD of Turkey in years between 2015 and 2030 with a smaller error rate. They used GDP, population and growth rate of Turkey in years between 2001 and 2014 and presented forecasted NGD of Turkey considering two different scenarios. Özmen et al. [16] proposed Multivariate Adaptive Regression Splines method and Conic Multivariate Adaptive Regression Splines to determine one-day ahead consumption of residential users in Ankara province of Turkey. They stated that their proposed methods for the natural gas industry can be used as two new competitive approaches. Sen et al. [17] proposed multiple regression models using socio-economic indicators such as gross domestic product and inflation rate. Beyca et al. [18] compared three alternative popular machine learning tools (multiple linear regression, ANN, support vector regression) for rigorous projection of natural gas consumption in the province of Istanbul. Furthermore, they stated that the support vector regression is much superior to ANN technique in view of statistical error.

There are other papers in the literature that use metaheuristic algorithms to forecast future energy demand of Turkey. Ceylan and Ozturk [19] proposed a GA for estimating energy demand of Turkey in years between 2020 and 2025 by using GNP, population, import and export figures of Turkey. Ünler [20] presented a particle swarm optimization technique as a swarm intelligence based algorithm in order to forecast the energy demand of Turkey. Öztürk et al. [21] proposed GAs for two different non-linear estimation models in order to forecast Turkey's electricity demand in years of 2002 and 2025 by using basic economic indicators of Turkey. Toksarı [22] proposed an Ant Colony Optimization algorithm as a multi-agent system for linear and quadratic forecasting equations of Turkey's energy demand until 2025 by using different scenarios. Toksarı [23] studied a hybrid algorithm including Ant Colony Optimization and Iterated Local Search algorithms for estimating Turkey's electricity domestic consumption until 2030 by using linear and quadratic forecasting equations. Canyurt and Öztürk [24] developed a GA for forecasting oil demand of Turkey by using some independent variables such as GNP, population, import, export, oil production, oil import and car, truck and bus sales figures of Turkey.

The studies in the literature have used some independent variables such as GDP, export, import and population in order to forecast future energy demands or consumption amounts. In this study, we use GDP at chained volume index (GDP_Index) where GDP in 2009 is accepted as 100\% because the national statistic institute of Turkey (TurkStat) [25] has stopped to calculate GDP at constant prices after 2016 and they changed their calculation method with GDP_Index where the value in 2009 is assumed reference values. GDP_Index is to demonstrate the real growth of a country by using previous term's prices.

In this study, NGD is a dependent variable and GDP_Index, population, import and export of Turkey are independent variables. Table 1 shows the values of NGD, population, import, export, and GDP_Index of Turkey between 1998 and 2017. Historical NGD values were taken from EnerData [3] and the rest of the values in Table 1 were taken from TurkStat [25]. As seen from Table 1, NGD has been increased 5 times in 20 years and each year's import value is greater than the export value. Because of its effects on current account deficit, the paper focuses on determining a forecasting equation for NGD of Turkey. With this motivation, the main purpose of this study is to determine the best coefficients with less statistical error for the forecasting equation for natural gas demand of Turkey. This paper suggests an $A B C$ algorithm for forecasting natural gas consumption in billion cubic meters $(\mathrm{bcm})$ for the years between 2018 and 2030 by using some historical indicators between 1998 and 2017. ABC algorithm is firstly used for determining coefficients of a forecasting equation for natural gas demand of Turkey. As far as we know, this study is the first study that uses $A B C$ method to forecast NGD demand of a country. Some researchers have used metaheuristic algorithms such as GA [13], SA [8], SAGA [13] and Breeder [15] algorithms for forecasting NGD of Turkey. Most of the used algorithms having less statistical error are either an evolutionary algorithm or hybrid algorithm using an evolutionary algorithm. $A B C$ algorithm was initially designed for continuous optimization problems. Therefore such a strong metaheuristic algorithm in the literature should be used for a vital problem of the countries having current account deficit like Turkey. A linear regression model is also established 
Table 1 The values of NGD, population, import, export, GDP_Index of Turkey between 1998 and $2017[3,25]$

\begin{tabular}{llllll}
\hline Year & NGD $(\mathrm{bcm})$ & $\begin{array}{l}\text { GDP_Index } \\
{[2009=100]}\end{array}$ & Population $10^{6}$ & Import $10^{9}$ & Export $10^{9}$ \\
\hline 1998 & 10.35 & 71.07 & 65.00 & 45.92 & 26.97 \\
1999 & 12.54 & 68.66 & 66.43 & 40.67 & 26.58 \\
2000 & 14.84 & 73.22 & 67.42 & 54.50 & 27.77 \\
2001 & 15.94 & 68.85 & 68.37 & 41.40 & 31.33 \\
2002 & 17.59 & 73.28 & 69.30 & 51.55 & 36.06 \\
2003 & 21.18 & 77.39 & 70.23 & 69.34 & 47.25 \\
2004 & 22.44 & 84.85 & 71.15 & 97.54 & 63.16 \\
2005 & 27.37 & 92.50 & 72.97 & 116.77 & 73.47 \\
2006 & 31.18 & 99.07 & 69.42 & 139.57 & 85.53 \\
2007 & 36.60 & 104.06 & 70.59 & 179.06 & 107.27 \\
2008 & 36.65 & 104.94 & 71.52 & 201.96 & 132.03 \\
2009 & 35.12 & 100.00 & 72.56 & 140.93 & 102.14 \\
2010 & 38.13 & 108.49 & 73.72 & 185.54 & 113.88 \\
2011 & 44.69 & 120.54 & 74.72 & 240.84 & 134.90 \\
2012 & 45.25 & 126.32 & 75.63 & 236.54 & 152.46 \\
2013 & 45.91 & 137.04 & 76.67 & 251.66 & 151.80 \\
2014 & 48.72 & 144.12 & 77.69 & 242.17 & 157.61 \\
2015 & 48.06 & 152.90 & 78.74 & 207.23 & 143.83 \\
2016 & 46.33 & 157.76 & 79.81 & 198.61 & 142.53 \\
2017 & 53.44 & 169.50 & 80.81 & 233.79 & 156.99 \\
\hline & & & & &
\end{tabular}

to compare the efficiency of the proposed $A B C$ method. Results in Sects. 3 and 4 indicate that the proposed $A B C$ algorithm forecast NGD values with a less statistical error. Hence the $A B C$ algorithm can be used by decision or policymakers interested in natural gas projection because of its simple structure, applicability and results with less statistical error.

\section{Solution approaches}

In this section, two forecasting methods are introduced. The first method is linear regression to forecast NGD (LR NGD) values of years between 2018 and 2030 and the second one is $A B C$ to forecast NGD (ABC_NGD) values of years between 2018 and 2030. In order to compare the efficiency of solution approaches, the mean absolute percentage error (MAPE) values of all forecasted NGD by two approaches are used as seen in Eq. (1).

MAPE $=\frac{1}{n} \sum_{t=1}^{n}\left|\frac{A_{t}-F_{t}}{A_{t}}\right|$

where $A_{t}$ is the observed (real) NGD value in year $t$ $(t=1,2, \ldots, n)$ and $F_{t}$ is the forecasted NGD value in year $t$. Furthermore, relative errors (RE) are investigated for both solution approaches.

\subsection{Linear regression to forecast natural gas demand of Turkey}

An LR_NGD is modeled by using the data of 20 years from 1998 to 2017 illustrated in Table 1 in order to forecast future NGD of Turkey between 2018 and 2030. Let us assume $Y_{L R \_N G D}$ is the dependent variable that illustrates the forecasted NGDs of Turkey. In order to forecast $Y_{L R \_N G D}$ this paper uses four independent variables. These are GDP_Index, population, import and export values of Turkey between 1998 and 2017. These values are expressed as $X_{1}, X_{2}, X_{3}$ and $X_{4}$ in Eq. (2) that is modeled as LR_NGD.

$Y_{L R \_N G D}=\beta_{0}+\beta_{1} X_{1}+\beta_{2} X_{2}+\beta_{3} X_{3}+\beta_{4} X_{4}$

By using Minitab 17 statistic software, coefficients of independent variables in Eq. (2) are obtained as in Eq. (3).

$Y_{L R \_N G D}=-38.6+0.466 X_{1}+0.658 X_{2}+0.0473 X_{3}+0.1194 X_{4}$

\subsection{Artificial bee colony algorithm to forecast gas demand of Turkey}

The artificial bee colony $(A B C)$ algorithm is a swarm based metaheuristic algorithm that was introduced by Karaboga [26] for optimizing numerical problems. It was inspired by the intelligent foraging behavior of honey bees as seen in Fig. 1. As a well-known optimization approach, the $A B C$ 


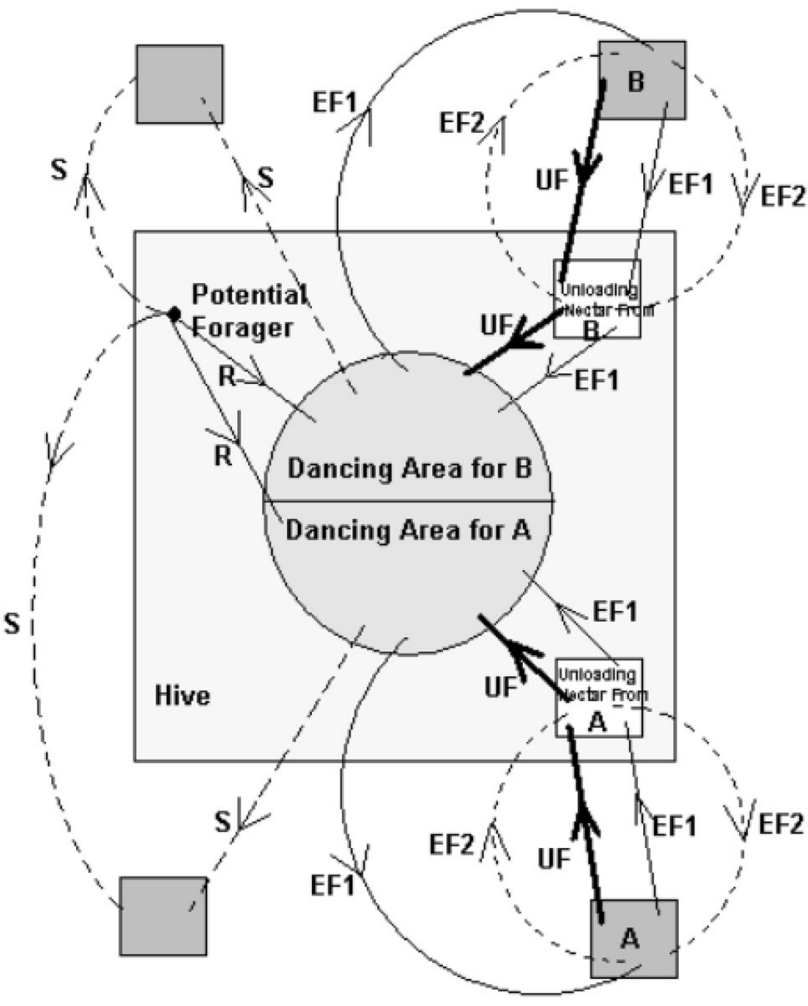

Fig. 1 The behaviour of honey bee foraging for nectar [26]

algorithm provides robust and near-optimal solutions. In the basic structure of $A B C$, there is a population including individuals called food positions and the individuals are evaluated with artificial bees in order to discover the best food resource or the area of good food resources. Artificial bees are classified into three groups as employed bees, onlooker bees and scout bees. As an assumption in $A B C$, the number of food resources is equal to the number of employed bees. In the initialization phase, scout bees fly randomly to food resources and discover these resources' nectar amounts. Then, employed bees exploit the food resources by using the knowledge gained from scout bees. Then feedbacks of employed bees are used for selection of effective food resources and onlooker bees fly to neighbors of effective food resources. If an employed bee whose food source has been exhausted, then that bee becomes a scout bee. This process goes on until a stopping condition has occurred. The general schema of the $A B C$ algorithm is given in Table 2. $A B C$ algorithm is a swarm-based algorithm that combines the benefits of local and global searches and it also has a feedback structure that disables to investigate bad solutions that have been previously investigated.

Karaboga proposed $A B C$ algorithm for continuous optimization problems where the objective is to maximize or minimize a $f\left(\overrightarrow{x_{m}}\right)$ function and each member $x_{m i}$ of $\overrightarrow{x_{m}}$ vector is bounded with a lower bound $l_{i}$ and an upper bound $u_{i} . \ln$ this study, each solution vector includes five members and these members are coefficients of independent variables. Let us assume $\vec{\beta}$ is a vector for independent variables and $\vec{\beta}=\left(\beta_{0}, \beta_{1}, \beta_{2}, \beta_{3}, \beta_{4}\right)$. There is a $(\vec{\beta})$ function as follows:

$f(\vec{\beta})=\sum_{t=1}^{n}\left|\left(A_{t}-F_{t}(\vec{\beta})\right) / A_{t}\right|$

where $F_{t}(\vec{\beta})$ is the forecasted NGD of Turkey for year $t$ by using $\vec{\beta}=\left(\beta_{0}, \beta_{1}, \beta_{2}, \beta_{3}, \beta_{4}\right)$ vector. $F_{t}(\vec{\beta})$ can be calculated as in Eq. (4).

$F_{t}(\vec{\beta})=\beta_{0}+\beta_{1} X_{1, t}+\beta_{2} X_{2, t}+\beta_{3} X_{3, t}+\beta_{4} X_{4, t}$

where $X_{1, t}, X_{2, t} X_{3, t}$ and $X_{4, t}$ are GDP_Index, population, import and export values of Turkey in year $t$. If we set the number of employed bees (number of food researches or individual in the population) in proposed ABC_NGD as $m$ then there are $m$ different $\vec{\beta}$ vectors such as $\vec{\beta}_{j}$ where $j=1,2, \ldots, m$. So the purpose of the forecasting is to find best-forecasted values close to the observed values then there is a best $\vec{\beta}^{*}$ vector that has optimum or near optimum as follows:

$f\left(\vec{\beta}^{*}\right)=\min \left(f\left(\vec{\beta}_{1}\right), f\left(\vec{\beta}_{2}\right), \ldots, f\left(\vec{\beta}_{m}\right)\right)$

In the initialization phase of ABC_NGD, all the vectors $\vec{\beta}_{j}$ $(j=1,2, \ldots, m$ and $:)$ are initialized by scout bees. Since
Table 2 Artificial bee colony algorithm for optimization problems [26]
Send the scouts onto the initial food sources

REPEAT

Send the employed bees onto the food sources and determine their nectar amounts

Calculate the probability value of the sources with which they are preferred by the onlooker bees

Send the onlooker bees onto the food sources and determine their nectar amounts

Stop the exploitation process of the sources exhausted by the bees

Send the scouts into the search area for discovering new food sources, randomly

Memorize the best food source found so far

UNTIL (requirements are met) 
each food source $\vec{\beta}_{j}$, is a set of coefficients to forecast NGD, each $\vec{\beta}_{j}$ vector holds $n$ variables, $\left(\beta_{j i}, i=0,1,2,3,4\right)$, which are to be optimized so as to find minimum $f\left(\vec{\beta}^{*}\right)$. Equation (7) is for initialization of $\beta_{j i} \forall i, j$ as follows:

$\beta_{j i}=I_{i}+\operatorname{rand}(0,1) *\left(u_{i}-I_{i}\right) \forall i, j$

where $I_{i}$ and $u_{i}$ are the lower and upper bound of the parameter $\beta_{j i}$, respectively.

Employed bees search for a new set of coefficients to forecast NGD $\left(\vec{v}_{j}\right)$ that have more suitable to forecast NGD with less error within the neighborhood of the existing set of coefficients $\left(\vec{\beta}_{j}\right)$ in their memory. Employed bees find a new $\vec{v}_{j}$ and they evaluate its profitability (fitness). Equation (8) is to determine a $\vec{v}_{j}$ by using existing $\vec{\beta}_{j}$.

$v_{j i}=\beta_{j i}+\phi_{j i}\left(\beta_{j i}-\beta_{k i}\right) \forall i, j$

where $\vec{\beta}_{k}$ is randomly selected set of coefficients, $i$ is randomly selected coefficient index in $\vec{\beta}_{j}$ and $\phi_{j i}$ is a random real number where $\phi_{j i} \in[-1,1]$. After producing a new set of coefficients $\vec{v}_{j}$, its fitness is calculated and a greedy selection is applied between $\vec{v}_{j}$ and $\vec{\beta}_{j}$. The fitness value of $\vec{\beta}_{j}$ is illustrated with fitness ${ }_{j}\left(\vec{\beta}_{j}\right)$ notation and it is calculated as follows:

fitness $_{j}\left(\vec{\beta}_{j}\right)=1 /\left(1+f\left(\vec{\beta}_{j}\right)\right)$

In the $A B C$ algorithm, employed bees give information about their own sets of coefficients to onlooker bees. Then, onlooker bees start selecting probabilistically their sets by using the feedback from employed bees. This selection phase is done with a fitness-based selecting technique and the probability $p_{j}$ of the set $\vec{\beta}_{j}$ can be determined as follows:

$p_{j}=\frac{\text { fitness }_{j}\left(\vec{\beta}_{j}\right)}{\sum_{j=1}^{m} \text { fitness }_{j}\left(\vec{\beta}_{j}\right)} \forall j$

After a set $\vec{\beta}_{j}$ for an onlooker bee is probabilistically chosen, a neighbourhood set $\vec{v}_{j}$ is determined by using Eq. (8), and its fitness value is computed by using Eq. (9). As in the employed bees phase, a greedy selection is applied between $\vec{v}_{j}$ and $\vec{\beta}_{j}$. Thus, the number of onlooker bees recruiting better solution spaces is increased. In this phase, to disable to inefficient set, a counter failure $e_{j}\left(\vec{\beta}_{j}\right)$ for each $\vec{\beta}_{j}$ takes places. If fitness $s_{j}\left(\vec{\beta}_{j}\right)$ is better than fitness $s_{j}\left(\vec{v}_{j}\right)$, then failure $_{j}\left(\vec{\beta}_{j}\right)$ increases one. If fitness $s_{j}\left(\vec{\beta}_{j}\right)$ is not better than fitness $_{j}\left(\vec{v}_{j}\right)$, then failure ${ }_{j}\left(\vec{\beta}_{j}\right)$ is set as zero. If failure $e_{j}\left(\vec{\beta}_{j}\right)$ reaches a pre-determined limit, then the employee bee dealing with $\vec{\beta}_{j}$ becomes a scout bee that abandons $\vec{\beta}_{j}$ and finds a random set of coefficients by using Eq. (7). The number of scout bees is generally limited for preventing the $A B C$ becoming a random search algorithm. The algorithm runs until a pre-determined stopping condition occurrence. In this study, the parameters of ABC_NGD are given in Table 3. For readers, there are lots of motivating and step by step examples presented by the $A B C$ algorithm homepage [27] to help them trace how the algorithm works for continuous optimization problems.

\section{Experimental results}

In this study, two models are used for forecasting NGD of Turkey in years between 2018 and 2030 by using historical indicators of Turkey dated between 1998 and 2017. After executing $A B C \_N G D$ in a standard desktop having $8 \mathrm{~GB}$ RAM and Intel i5 CPU, a forecasting equation is obtained as seen in Eq. (11). The proposed ABC_NGD was coded with C\# programming language in Visual Studio 2017. The second method is LR_NGD and its forecasting equation illustrated in Eq. (12) was obtained by using Minitab 17 statistic software in the same desktop.

$$
\begin{aligned}
Y_{A B C \_N G D}= & -88.3852-0.03963 X_{1} \\
& +1.49202 X_{2}+0.06665 X_{3}+0.06832 X_{4}
\end{aligned}
$$

$Y_{L R \_N G D}=-38.6+0.466 X_{1}+0.658 X_{2}+0.0473 X_{3}+0.1194 X_{4}$

The forecasted NGD values of each equation are given in Table 4. As seen from Table 4, MAPE value of $Y_{A B C} N G D$ is less than MAPE value of $Y_{L R \_N G D}$ when we consider only historical NGD values of Turkey between 1998 and 2017. $Y_{L R \_N G D}$ forecasting equation's MAPE value is $5.18 \%$. $Y_{A B C \_N G D}$ forecasting equation's MAPE value is $4.01 \%$ and it is a $22.56 \%$ better forecasting equation compared with $Y_{L R \_N G D}$ in view of MAPE values. Experimental results are given in Table 4. Figure 2 shows the forecasted values of

Table 3 Parameters of ABC_NGD

\begin{tabular}{ll}
\hline Parameters & Values \\
\hline Number of employed bees & 120 \\
Number of onlooker bees & 120 \\
Number of scout bees & 1 \\
Limit for failures of each bee & 300 \\
Stopping criteria & $10^{6}$ iterations \\
li for $\beta_{j i}$ where $i=(1,2,3,4)$ and $\forall j$ & -2 \\
$u i$ for $\beta_{j i}$ where $i=(1,2,3,4)$ and $\forall j$ & 2 \\
$l i$ for $\beta_{j i}$ where $i=0$ and $\forall j$ & -100 \\
$u i$ for $\beta_{j i}$ where $i=0$ and $\forall j$ & 100 \\
\hline
\end{tabular}


Table 4 Experimental results and forecasts of proposed solution approaches

\begin{tabular}{llllll}
\hline Year & Observed NGD & LR_NGD & RE of LR_NGD & ABC_NGD & RE of ABC_NGD \\
\hline 1998 & 10.351 & 12.874 & 0.244 & 10.677 & 0.031 \\
1999 & 12.537 & 13.408 & 0.069 & 12.532 & 0.000 \\
2000 & 14.835 & 15.068 & 0.016 & 14.835 & 0.000 \\
2001 & 15.944 & 15.295 & 0.041 & 15.794 & 0.009 \\
2002 & 17.588 & 17.158 & 0.024 & 18.006 & 0.024 \\
2003 & 21.182 & 20.139 & 0.049 & 21.183 & 0.000 \\
2004 & 22.444 & 24.326 & 0.084 & 25.227 & 0.124 \\
2005 & 27.373 & 28.020 & 0.024 & 29.628 & 0.082 \\
2006 & 31.183 & 28.509 & 0.086 & 26.407 & 0.153 \\
2007 & 36.599 & 33.975 & 0.072 & 32.077 & 0.124 \\
2008 & 36.645 & 38.667 & 0.055 & 36.647 & 0.000 \\
2009 & 35.118 & 32.666 & 0.070 & 32.280 & 0.081 \\
2010 & 38.128 & 37.337 & 0.021 & 37.458 & 0.018 \\
2011 & 44.686 & 43.682 & 0.022 & 43.600 & 0.024 \\
2012 & 45.254 & 46.443 & 0.026 & 45.633 & 0.008 \\
2013 & 45.912 & 48.264 & 0.051 & 47.724 & 0.039 \\
2014 & 48.723 & 49.510 & 0.016 & 48.723 & 0.000 \\
2015 & 48.055 & 47.311 & 0.015 & 46.663 & 0.029 \\
2016 & 46.331 & 47.679 & 0.029 & 47.401 & 0.023 \\
2017 & 53.437 & 52.275 & 0.022 & 51.762 & 0.031 \\
& & Total RE & 1.036 & Total RE & 0.802 \\
& & MAPE & 0.0518 & MAPE & 0.0401 \\
\hline
\end{tabular}

both functions and observed values belong to the years between 1998 and 2017.

The total absolute relative error value of $Y_{L R_{-} N G D}$ is higher than $Y_{A B C}{ }_{N G D}$ and as seen from Table 4, some of RE values of $Y_{A B C \_N G D}$ are so close to zero. The biggest deviation for $Y_{A B C \_N G D}$ is $\pm 1.53 \%$ and the biggest deviation for $Y_{L R \_N G D}$ is $\pm 2.44 \%$. In order to compare efficiency of the proposed ABC_NGD, an ANOVA analysis was made under $95 \%$ confidence level. As factors, methodfactor (observed values and ABC_NGD) and year-factor are used. $P$ value for the method-factor was calculated as 0.366 as seen in Table 5 so we cannot reject the null hypothesis that states there is no difference between methods because $P$ value $\geq 0.05$.
Fig. 2 Obtained NGD values of both solution approaches after training and observed NGD values

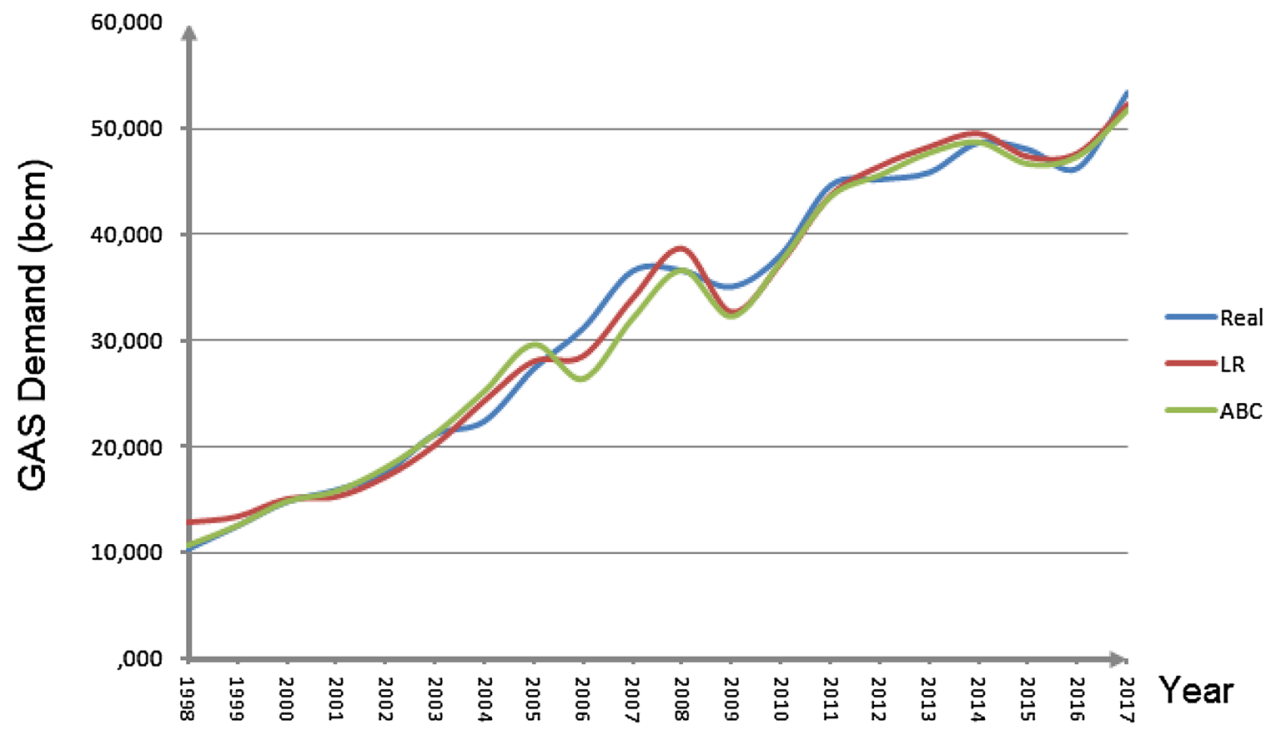

SN Applied Sciences 
Table 5 Two-way ANOVA analysis for observed values and values obtained from the proposed $A B C$

\begin{tabular}{lrrrrrrr}
\hline Source & DF & \multicolumn{1}{c}{ Seq SS } & Contribution (\%) & Adj SS & Adj MS & F-value & $p$ value \\
\hline Method & 1 & 1.63 & 0.02 & 1.63 & 1.627 & 0.86 & 0.366 \\
Year & 19 & 7144.06 & 99.48 & 7144.06 & 376.003 & 198.07 & 0.000 \\
Error & 19 & 36.07 & 0.50 & 36.07 & 1.898 & & \\
Total & 39 & 7181.75 & 100.00 & & & & \\
\hline
\end{tabular}

Table 6 Scenarios for forecasting NGD of Turkey in years between 2018-2030

GDP_Index Population (\%) Export (\%) Import (\%) (\%)

\begin{tabular}{llllr}
\hline Scenario 1 & 5 & 1.5 & 9 & 11 \\
Scenario 2 & 3.5 & 1 & 6 & 9 \\
\hline
\end{tabular}

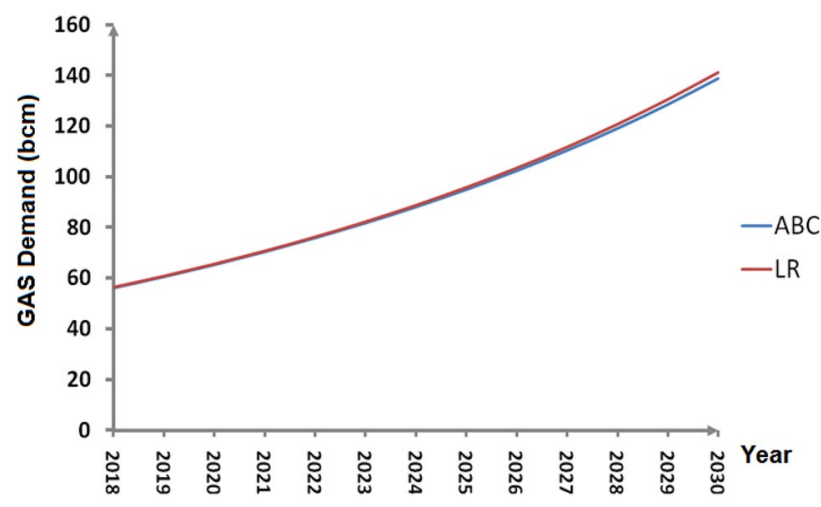

Fig. 3 Natural gas demand for Scenario1

\section{Scenarios for forecasting NGD of Turkey}

In this section, we used two scenarios in order to forecast Turkey's NGD for years between 2018 and 2030. The scenarios are given in Table 6 for GDP_Index, population, export and import values in years between 2018 and 2030. The forecasted values of both methods for Scenario 1 are given in Fig. 3 and for Scenario 2 are given in Fig. 4. Proportions for GDP_Index, population, export and import in two scenarios simply state assumptions for growth rates of GDP_Index, population, export and import values of Turkey in years between 2018 and 2030. By using these growth rates in scenarios and coefficients obtained from proposed methods, NGD values are forecasted as seen in Figs. 3 and 4.

As seen in Figs. 3 and 4, forecasted NGD values are almost the same so it seems that there are small differences between ABC_NGD and LR_NGD methods for forecasting. In order to determine whether there is a difference for these methods for each scenario, two-way

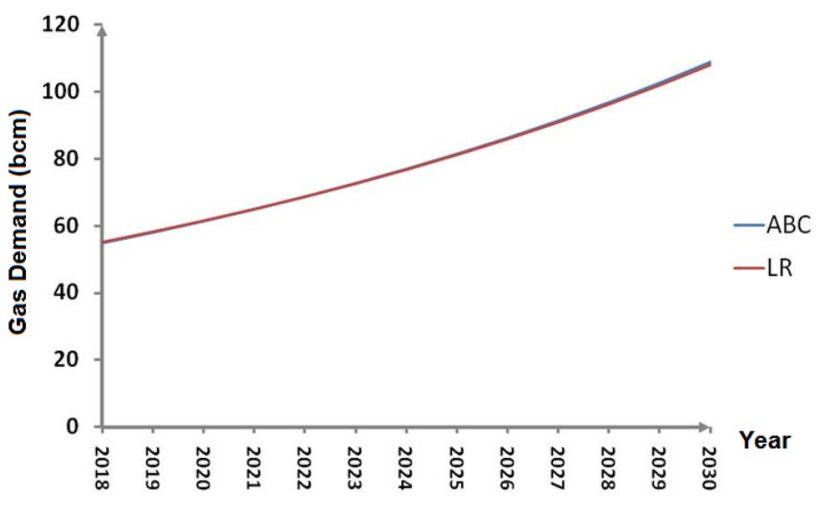

Fig. 4 Natural gas demand for Scenario2

ANOVA analyzes using methods and years as factors are made where the null hypothesis states there is no difference between methods (means obtained different methods are the same). Results of ANOVA analyzes are given in Tables 7 and 8 for scenarios. For Scenario 1, an ANOVA analysis made within $95 \%$ confidence level for determining these methods' difference gives a $p$-value $=0.000$ so we can say that these methods are different. For Scenario 2, an ANOVA analysis made within $95 \%$ confidence level and the $p$ value $=0.221$ so we cannot reject the null hypothesis that states there is no difference between methods because of $p$ value $\geq 0.05$. Although each method's forecasted NGD values are so close for Scenario 1, there is a difference between ABC_NGD and LR_NGD.

\section{Conclusion}

Most of natural gas used in residential and industrial areas of Turkey has been imported from other countries such as Russia, Iran and Azerbaijan. In order to create and manage an energy strategy, it is obligatory to know how much natural gas consumed previously and how much it will be consumed. Turkey has a chronical problem named current account deficit since the $1980 \mathrm{~s}$ and Tukey has dealt with economic crises in 1994, 2000 and 2001. For such a country, it is so important to estimate how much natural gas, a vital energy source, will be consumed with less statistical error. Therefore $A B C$ algorithm that is strong and initially generated for continuous optimization problem 
Table 7 Two-way ANOVA analysis for experimental results of scenario 1

\begin{tabular}{lrrrrrrr}
\hline Source & DF & \multicolumn{1}{c}{ Seq SS } & Contribution (\%) & Adj SS & Adj MS & F value & $p$ value \\
\hline Method & 1 & 7.6 & 0.04 & 7.6 & 7.60 & 29.93 & 0.000 \\
Year & 12 & 17588.4 & 99.94 & 17588.4 & 1465.70 & 5773.19 & 0.000 \\
Error & 12 & 3.0 & 0.02 & 3.0 & 0.25 & & \\
Total & 25 & 17599.1 & 100.00 & & & & \\
\hline
\end{tabular}

Table 8 Two-way ANOVA analysis for experimental results of scenario 2

\begin{tabular}{lrrrrrrr}
\hline Source & DF & \multicolumn{1}{c}{ Seq SS } & Contribution (\%) & Adj SS & Adj MS & F value & $p$ value \\
\hline Method & 1 & 0.14 & 0.00 & 0.14 & 0.138 & 1.67 & 0.221 \\
Year & 12 & 7214.35 & 99.98 & 7214.35 & 601.196 & 7266.83 & 0.000 \\
Error & 12 & 0.99 & 0.01 & 0.99 & 0.083 & & \\
Total & 25 & 7215.48 & 100.00 & & & & \\
\hline
\end{tabular}

is selected in order to forecast natural gas demand of Turkey for years between 2018 and 2030. A forecasting equation obtained with $A B C \_N G D$ algorithm was compared to an LR_NGD forecasting equation. By using MAPE and RE values of proposed forecasting equation methods, it was determined that ABC_NGD has less MAPE and RE values. Even if both forecasting equations' coefficients are different, forecasted NGD values are so close. Two ANOVA analyses made for determining differences between two methods showed us that these methods are different by means for Scenario 1 and these are not different by means for Scenario 2. Therefore, we suggest future researchers wanted to use these methods in their study that more data should be included in the analysis to define the difference between these methods because there is a certain relationship between the amounts of data involved in analysis and obtained coefficients that give forecast values with the less statistical error. Considering MAPE and RE values, $A B C \_N G D$ is a better method for forecasting. This proposed $A B C$ algorithm can be used in further researches to forecast other important energy resources' consumptions such as electricity, oil, and coal. Furthermore, the proposed method can be considered to use of other regression equations such as quadratic, nonlinear or logistic.

\section{Compliance with ethical standards}

Conflict of interest The author declared that there is no conflict of interest.

\section{References}

1. Boran FE (2015) Forecasting natural gas consumption in Turkey using grey prediction. Energy Sources Part B Econ Plan Policy 10:208-213. https://doi.org/10.1080/15567249.2014.893040
2. Hacisalihoglu B (2008) Turkey's natural gas policy. Energy Policy 36:1867-1872. https://doi.org/10.1016/j.enpol.2008.02.001

3. EnerData (2019) EnerData. https://www.enerdata.net/. Accessed 1 Mar 2019

4. Erdogdu E (2010) Natural gas demand in Turkey. Appl Energy 87:211-219. https://doi.org/10.1016/j.apenergy.2009.07.006

5. Sarak H, Satman A (2003) The degree-day method to estimate the residential heating natural gas consumption in Turkey: a case study. Energy 28:929-939. https://doi.org/10.1016/S0360 $-5442(03) 00035-5$

6. Ozturk HK, Canyurt OE, Hepbasli A, Utlu Z (2004) Residentialcommercial energy input estimation based on genetic algorithm (GA) approaches: an application of Turkey. Energy Build 36:175-183. https://doi.org/10.1016/j.enbuild.2003.11.001

7. Aras N (2008) Forecasting residential consumption of natural gas using genetic algorithms. Energy Explor Exploit 26:241266. https://doi.org/10.1260/014459808787548705

8. Toksari M (2010) Predicting the natural gas demand based on economic indicators: case of Turkey. Energy Sources Part A Recover Util Environ Eff 32:559-566. https://doi. org/10.1080/15567030802578823

9. Olgun MO, Ozdemir G, Aydemir E (2012) Forecasting of Turkey's natural gas demand using artifical neural networks and support vector machines. Energy Educ Sci Technol Part A Energy Sci Res 30:15-20

10. Taşpinar F, Çelebi N, Tutkun N (2013) Forecasting of daily natural gas consumption on regional basis in Turkey using various computational methods. Energy Build 56:23-31. https://doi. org/10.1016/j.enbuild.2012.10.023

11. Melikoglu M (2013) Vision 2023: forecasting Turkey's natural gas demand between 2013 and 2030. Renew Sustain Energy Rev 22:393-400. https://doi.org/10.1016/j.rser.2013.01.048

12. Akpinar M, Yumusak N (2016) Year ahead demand forecast of city natural gas using seasonal time series methods. Energies. https://doi.org/10.3390/en9090727

13. Ozdemir G, Aydemir E, Olgun MO, Mulbay Z (2016) Forecasting of Turkey natural gas demand using a hybrid algorithm. Energy Sources Part B Econ Plan Policy 11:295-302. https:// doi.org/10.1080/15567249.2011.611580

14. Akpinar M, Adak MF, Yumusak N (2017) Day-ahead natural gas demand forecasting using optimized $A B C$-based neural network with sliding window technique: the case study of regional basis in Turkey. Energies. https://doi.org/10.3390/ en10060781

15. Karadede Y, Ozdemir G, Aydemir E (2017) Breeder hybrid algorithm approach for natural gas demand forecasting model. 
Energy 141:1269-1284. https://doi.org/10.1016/j.energ y.2017.09.130

16. Özmen A, Yılmaz Y, Weber G-W (2018) Natural gas consumption forecast with MARS and CMARS models for residential users. Energy Econ 70:357-381. https://doi.org/10.1016/j.eneco .2018.01.022

17. Sen D, Günay ME, Tunç KMM (2019) Forecasting annual natural gas consumption using socio-economic indicators for making future policies. Energy. https://doi.org/10.1016/j.energ y.2019.02.130

18. Beyca OF, Ervural BC, Tatoglu E et al (2019) Using machine learning tools for forecasting natural gas consumption in the province of Istanbul. Energy Econ 80:937-949. https://doi. org/10.1016/j.eneco.2019.03.006

19. Ceylan H, Ozturk HK (2004) Estimating energy demand of Turkey based on economic indicators using genetic algorithm approach. Energy Convers Manag 45:2525-2537. https://doi. org/10.1016/j.enconman.2003.11.010

20. Ünler A (2008) Improvement of energy demand forecasts using swarm intelligence: the case of Turkey with projections to 2025. Energy Policy 36:1937-1944. https://doi.org/10.1016/j.enpol .2008.02.018

21. Ozturk HK, Ceylan H, Canyurt OE, Hepbasli A (2005) Electricity estimation using genetic algorithm approach: a case study of Turkey. Energy 30:1003-1012. https://doi.org/10.1016/j.energ y.2004.08.008
22. Toksari MD (2007) Ant colony optimization approach to estimate energy demand of Turkey. Energy Policy 35:3984-3990. https:// doi.org/10.1016/j.enpol.2007.01.028

23. Toksari MD (2016) A hybrid algorithm of ant colony optimization (ACO) and Iterated Local Search (ILS) for estimating electricity domestic consumption: case of Turkey. Int J Electr Power Energy Syst 78:776-782. https://doi.org/10.1016/j.ijepes.2015.12.032

24. Canyurt OE, Öztürk HK (2006) Three different applications of genetic algorithm (GA) search techniques on oil demand estimation. Energy Convers Manag 47:3138-3148. https://doi. org/10.1016/j.enconman.2006.03.009

25. TurkStat (2019) Turkish statistical institute. http://www.turkstat. gov.tr. Accessed 1 Mar 2019

26. Karaboga D (2005) An idea based on honey bee swarm for numerical optimization. Technical Report TR06, Erciyes University, Engineering Faculty, Computer Engineering Department

27. Karaboga $D$ (2019) Artificial bee colony (ABC) algorithm homepage. https://abc.erciyes.edu.tr/. Accessed 21 May 2019

Publisher's Note Springer Nature remains neutral with regard to jurisdictional claims in published maps and institutional affiliations. 